\title{
The role of salvage lymph node dissection and PSMA-PET in recurrent prostate cancer
}

\author{
Nikolaos Kalampokis ${ }^{1}$, Nikolaos Grivas ${ }^{1,2}$ \\ ${ }^{1}$ Department of Urology, Hatzikosta General Hospital, Ioannina, Greece; ${ }^{2}$ Department of Urology, Netherlands Cancer Institute, Amsterdam, The \\ Netherlands \\ Correspondence to: Nikolaos Grivas. Department of Urology, The Netherlands Cancer Institute-Antoni van Leeuwenhoek Hospital, Amsterdam, The \\ Netherlands. Email: n.grivas@nki.nl. \\ Provenance and Peer Review: This article was commissioned and reviewed by the Guest Section Editor, Dr. Xiao Li (Department of Urology, Jiangsu \\ Cancer Hospital \& Jiangsu Institute of Cancer Research \& Affiliated Cancer Hospital of Nanjing Medical University, Nanjing, China). \\ Comment on: Hanske J, Ostholt J, Roghmann F, et al. Salvage lymph node dissection in hormone-naïve men: How effective is surgery? Urol Oncol \\ 2019;37:812.e17-812.e24.
}

Submitted Jan 13, 2020. Accepted for publication Feb 06, 2020.

doi: 10.21037 /gs.2020.02.12

View this article at: http://dx.doi.org/10.21037/gs.2020.02.12

Although up to $50 \%$ of the patients undergoing radical prostatectomy (RP) for clinically localized prostate cancer (PCa) are expected to experience biochemical recurrence sometime in their life (1), the introduction of novel techniques like the PSMA PET/CT can improve the diagnosis at the stage of lymph nodes-only recurrence (2-4). As we recently showed, the combination of PSMA PET with extended lymph node dissection has 94\% accuracy for nodal staging in primary diagnosed intermediate- and high-risk PCa, while adding sentinel node biopsy in negative PSMA PET/CT increased the combined sensitivity to $100 \%$ (5). While the mainstay of treatment for these patients has traditionally been the administration of androgen deprivation therapy (ADT) (6), new approaches such as salvage lymph node dissection (SLND) have started coming to the front aiming to delay palliative ADT or improve survival in carefully selected patients $(7,8)$.

In fact, SLND has been recently introduced in EAU guidelines (6) as a possible treatment option for patients with lymph node-confined recurrence, although it is clearly stated that both its efficacy and its impact on survival remain to be proven (9). In an effort to assess the real oncological benefit of SLND and the accuracy of PSMA PET/ CT, Hanske et al. published recently a single-institution retrospective study comprising 43 hormone-naive patients who underwent SLND over a period of 6 years (10). Interestingly, they reported a disappointing percentage of biochemical response after SLND (namely $18.6 \%$ of the patients), while sensitivity and PPV of PSMA PET/CT were found to be $32 \%$ and $44 \%$ respectively. According to the authors, the aforementioned findings could be attributed to the fact that, unlike previous studies, their cohort was devoid of cases with hormone manipulation after RP.

Can it be concluded, then, that the introduction of elective SLND is about to reach a dead end? Probably not. Although we should have in mind that Hanske's study was the first to include only hormone-naive patients, we should certainly not ignore the results of previous studies like the systematic review conducted by Ploussard et al. (11), which reported that SLND was associated with a non-negligible percentage of early biochemical response in patients with node-only recurrence. While outcomes of current studies seem to be contradictory, it is of utmost importance that we focus our efforts on finding those patients that could benefit the most from this novel approach. Towards this direction, Fossati et al. (12) developed a risk stratification model estimating the risk of early failure after SLND. As expected, they concluded that SLND should be avoided in patients with high risk for early biochemical recurrence. They also suggest that the patients should definitely be informed of the experimental nature of the procedure.

In conclusion, before widely accepting or rejecting the role of SLND, we should await the results of large randomized controlled trials lacking heterogeneity in 
terms of patient selection, use of adjuvant therapies and surgical template. Moreover, these studies should obviously interpret their results by using common end-points, so that we can safely reach a consensus about the efficacy of this new therapeutic approach.

\section{Acknowledgments}

Funding: None.

\section{Footnote}

Conflicts of Interest: Both authors have completed the ICMJE uniform disclosure form (available at http://dx.doi. org/10.21037/gs.2020.02.12). The authors have no conflicts of interest to declare.

Ethical Statement: The authors are accountable for all aspects of the work in ensuring that questions related to the accuracy or integrity of any part of the work are appropriately investigated and resolved.

Open Access Statement: This is an Open Access article distributed in accordance with the Creative Commons Attribution-NonCommercial-NoDerivs 4.0 International License (CC BY-NC-ND 4.0), which permits the noncommercial replication and distribution of the article with the strict proviso that no changes or edits are made and the original work is properly cited (including links to both the formal publication through the relevant DOI and the license). See: https://creativecommons.org/licenses/by-nc-nd/4.0/.

\section{References}

1. Porter CR, Kodama K, Gibbons RP, et al. 25-year prostate cancer control and survival outcomes: a 40-year radical prostatectomy single institution series. J Urol 2006;176:569-74.

2. van Leeuwen PJ, Stricker P, Hruby G, et al. (68) Ga-PSMA has a high detection rate of prostate cancer recurrence outside the prostatic fossa in patients being considered for salvage radiation treatment. BJU Int 2016;117:732-9.

3. Eiber M, Maurer T, Souvatzoglou M, et al. Evaluation of Hybrid ${ }^{68}$ Ga-PSMA Ligand PET/CT in 248 Patients with Biochemical Recurrence After Radical Prostatectomy. J Nucl Med 2015;56:668-74.

4. Kimura S, Abufaraj M, Janisch F, et al. Performance of [68Ga] Ga-PSMA 11 PET for detecting prostate cancer in the lymph nodes before salvage lymph node dissection: a systematic review and meta-analysis. Prostate Cancer Prostatic Dis 2020;23:1-0.

5. Hinsenveld FJ, Wit EMK, van Leeuwen PJ, et al. ProstateSpecific Membrane Antigen PET/CT Combined with Sentinel Node Biopsy for Primary Lymph Node Staging in Prostate Cancer. J Nucl Med 2020;61:540-5.

6. Cornford P, Bellmunt J, Bolla M, et al. EAU-ESTROSIOG Guidelines on Prostate Cancer. Part II: Treatment of Relapsing, Metastatic, and Castration-Resistant Prostate Cancer. Eur Urol 2017;71:630-42.

7. Tilki D, Mandel P, Seeliger F, et al. Salvage lymph node dissection for nodal recurrence of prostate cancer after radical prostatectomy. J Urol 2015;193:484-90.

8. Karnes RJ, Murphy CR, Bergstralh EJ, et al. Salvage lymph node dissection for prostate cancer nodal recurrence detected by 11C-choline positron emission tomography/ computerized tomography. J Urol 2015;193:111-6.

9. Ploussard G, Almeras C, Briganti A, et al. Management of Node Only Recurrence after Primary Local Treatment for Prostate Cancer: A Systematic Review of the Literature. J Urol 2015;194:983-8.

10. Hanske J, Ostholt J, Roghmann F, et al. Salvage lymph node dissection in hormone-naïve men: How effective is surgery? Urol Oncol 2019;37:812.e17-812.e24.

11. Ploussard G, Gandaglia G, Borgmann H, et al. Salvage Lymph Node Dissection for Nodal Recurrent Prostate Cancer: A Systematic Review. Eur Urol 2019;76:493-504.

12. Fossati N, Suardi N, Gandaglia G, et al. Identifying the Optimal Candidate for Salvage Lymph Node Dissection for Nodal Recurrence of Prostate Cancer: Results from a Large, Multi-institutional Analysis. Eur Urol 2019;75:176-83.
Cite this article as: Kalampokis N, Grivas N. The role of salvage lymph node dissection and PSMA-PET in recurrent prostate cancer. Gland Surg 2020;9(4):1080-1081. doi: 10.21037/ gs.2020.02.12 